\title{
Effect of Caregiver's Expressed Emotions on Clinical Outcomes of Patients with Bipolar Disorder
}

\section{Ola Arafa Mohammed ${ }^{1}$, Sayeda Ahmed Abd El-Latief ${ }^{2}$, Mawaheb Mahmoud Zaki ${ }^{3}$ and Doha Abdel-Baseer Mahmoud ${ }^{4}$}

(1) Head Nurse in Psychiatric Mental Health Hospital at Benha City (2) Professor of Psychiatric and Mental Health Nursing Faculty of Nursing Cairo University (3) Assistant Professor of Psychiatric \& Mental Health Nursing Faculty of Nursing-Benha University (4) Lecturer of Psychiatric and Mental Health Nursing Faculty of Nursing Benha University

\section{Abstract}

Background: Bipolar disorder is a mental disorder characterized by intermittent episodes of mania or depression, with an absence of symptoms in between. During these episodes, people with bipolar disorder exhibit disruptions in normal mood, psychomotor activity, the level of physical activity that is influenced by mood Aim of the study: Was to assess the effect of caregiver's expressed emotions on clinical outcomes of patients with bipolar disorder. Research design: Descriptive/ correlations design was used in this study. Setting: Psychiatric and Mental Health Hospital in Benha city, Qalubia Governorate. Subject: A purposive sample consist of (80) bipolar disorder patients and their caregivers from the previous study setting. Tools: Three tools were used for data collection. Tool (1):- a structured interviewing questionnaire sheet was used to collect data about socio demographic and clinical characteristics of the studied sample. Tool (2):- Camber Well Family Interview to assess patients families about their response to patients illness. Tool (3):- to assess symptoms of patients with mood disorders. Results: There was a positive statistically correlation between total caregivers' expressed emotion and total patients' clinical outcomes. Conclusion: Patients with high- expressed emotion caregivers have been found to have poorer management of their health condition and poorer clinical outcome than those with low- expressed emotion. Recommendations: Designing a systematically continuous family intervention programs in psychiatric hospitals that provide proper information and psychological support

Key words: bipolar disorder, caregivers' expressed emotion, clinical outcome.

\section{Introduction:}

Bipolar disorder is a common, severe, and chronic psychiatric condition. The lifetime prevalence of bipolar disorders is $2.6 \%$ to $6.5 \%$. Bipolar I disorder is diagnosed when a patient has experienced at least one manic episode lasting at least one week and involving a distinct and abnormal elevated or irritable mood, whereas bipolar II disorder is diagnosed when a one hypomanic episode. The impact of episodes of mania, hypomania, and depression is enormous (Craddock and Sklar 2016).
Late adolescence and early adulthood are peak years for the onset of bipolar disorder. The condition is characterized by intermittent episodes of mania or depression, with an absence of symptoms in between. During these episodes, people with bipolar disorder exhibit disruptions in normal mood, psychomotor activity-the level of physical activity that is influenced by mood like constant fidgeting with mania or slowed movements with depression, circadian rhythm, and cognition. Mania can present with varying levels of mood disturbance, 
ranging from euphoria that is associated with "classic mania" to dysphoria and irritability (Bortolato et al, 2020).

Bipolar affective disorder is a common major mental disorder and it is chronic in nature. The degree of ability or disability in chronic mental disorder varies over time and across different life domains. The likely course and outcome of mental disorders vary, and depend on numerous factors related to the disorder itself, the individual as a whole, and the social environment. Bipolar disorder is the sixth leading cause of disability worldwide and has a lifetime prevalence of about 1 to $3 \%$ in the general population. Bipolar spectrum disorders include: bipolar I disorder, bipolar II disorder, cyclothymic disorder and cases where subthreshold symptoms are found to cause clinically significant impairment or distress (Muneer, 2016)

Expressed emotion is a measure that has been used to assess the quality of the relationship between patient and their key relative. It has been shown to be strongly predictive of clinical outcome in a range of psychiatric and medical disorders. Families who have high expressed emotion experience mixed emotions as they experience cycles of hope and disappointment. High expressed emotion careers appear to perceive their caring situation as more stressful than low expressed emotion careers. They typically experience considerable subjective burden. So, family members may react with hostile feelings that are associated with a poor prognosis for patient (Leff et al, 2018).

Expressed emotion is a descriptive concept relating to the emotional climate of interpersonal relationships, an elaboration of the idea that emotions creates an atmosphere within which social interaction occurs. Expressed emotion is not a measure of emotional expressiveness. Rather, it is a measure of the extent to which an individual family member of patient talks about that patient in a critical or aggressive manner or in a way that indicates marked emotional over involvement (Kwok, et al, 2016).

Caregivers play a vital role in reducing costs and resources on the healthcare system by caring for loved ones at home. Therefore, it is essential to take care of caregivers to reduce the long-term effects of caregiver burden. Psychiatric nurses might teach families who have patients with bipolar disorder about the process of negative expressed emotion that often associates with bipolar disorder, the psychiatric nurses also play important role in providing family caregivers with basic information that help them to deal better with the patient and reduce the negative expressed emotion (Di Giacomo et al, 2017)..

Caregivers are classified as high- or low expressed emotion based on the presence of criticism, hostility or emotional over involvement. Positive attributes are rated and may have some predictive role, but are not conventionally involved in classifying EE. If the caregiver is above the threshold for criticism, and makes hostile remarks, and shows evidence of marked Emotional over involvement (Fallon et al, 2019)

Studies showed that the care of patients can become a significant burden for families, including increased stress, worsted subjective well-being, physical deterioration, and selfvalue reduction. Patient's families experienced both objective and subjective burden, which can foster family dysfunction. The severity of burden was closely related to pathological behavior of patients, caregivers experienced severe burden in taking care of patient with mental illness (Lowyck, et al 2019).

\section{Significance of the study:}

By the year 2020, bipolar disorder will be the sixth leading cause of disability 


\section{Ola Arafa, Sayeda Ahmed, Mawaheb Mahmoud and Doha Abdel-Baseer}

worldwide among all medical illnesses. The illness is highly recurrent, with $60 \%$ of patients experiencing recurrences of mania or depression within 2 years and up to $75 \%$ experiencing recurrences within 5 years. Patients experience significant symptoms during approximately half of the weeks of their lives and have multiple impairments in school, at work, and in relationships. Up to $15 \%$ die by suicide, and as many as $50 \%$ attempt suicide one or more times. Current thinking about the relapse-remission course of bipolar disorder emphasizes a biopsychosocial model that incorporates the interactive roles of genetic vulnerability, biological predispositions, family or life events stress, and psychological vulnerability. Family stress has been operationalized as whether or not the patient resides with relatives characterized by high expressedemotion attitudes (Miklowitz \&Chung, 2016)

\section{Aim of the study:}

The aim of the study is to assess the effect of caregiver's expressed emotions on clinical outcomes of patients with bipolar disorder.

\section{Subject and Methods:}

\section{Research question:}

What are the forms of expressed emotions of the caregivers?

What is the relationship between the caregiver's expressed emotion and clinical outcomes of patients with bipolar disorder?

\section{Research design:}

A descriptive correlational design was used in this study.

\section{Setting:}

The present study was conducted at the Psychiatric and Mental Health Hospital in Benha city, Qalubia Governorate, which is affiliated to General Secretariat of Mental Health in Egypt.

\section{Sample:}

1- Sample size:

The sample consist of (80) bipolar disorder patients and their caregivers

\section{2- Sample type:}

Purposive sample included in this study according to the following criteria:

- Bipolar disorder diagnosis.

- Caregivers who caring of bipolar disorder patients.

- Both genders.

- Willingness to participate in the study.

\section{Tools for data collection:}

Tool (I): A structured Interviewing Questionnaire Sheet:

This tool was developed by the researcher based on pertinent literature to elicit information about socio-demographic and clinical data:

\section{Part 1- Socio-demographic data of patients} such as, (age, gender, marital status, level of education and occupation).

Part 2- Socio-demographic data of caregivers it includes (age, gender, level of education, working status, family size, family income).

Part 3- Clinical data of patients such as (duration of illness, age at onset of the illness and number of hospital admission).

\section{Tool (II): Camber Well Family Interview}

This tool was developed by Vaughn and Left, (1976) it was translated into Arabic version by Abo-Almagied, (1993) it used to assess patients families about their response to patients illness. This tool modified by the researcher to facilitate the data analysis process, it consisted of 12 subscale. These response alternative were always, sometimes, rarely and never, these response score 3,2, 1and 0 . 
Scoring system

- 0-28: low patient behavior.

- 29-48: mild patient behavior.

- 49-68: moderate patient behavior.

- 69-84: sever patient behavior.

\section{Scoring system}

- 0-35: low response to patient illness.

- 36-60: mild response to patient illness.

- 61-85: moderate response to patient illness.

- 86-105: high response to patient illness.

\section{Tool (III): The Mood Disorder questionnaire}

The mood disorder questionnaire is developed by Hirschfeld,et al.,(2000) it was translated into Arabic version by El-Rasheed Hospital, (2019) it used to assess symptoms of patients with mood disorders. This tool includes 13 items. These response alternative was yes, no these response score were 1,0

Scoring system

- 0-4: low symptoms of mood disorder.

- 5-9: moderate symptoms of mood disorder.

- 10-13: high symptoms of mood disorder.

\section{Validity}

To achieve the criteria of trustworthiness of the data collection tools in this study, tools were tested and evaluated for content validity. Content validity was tested by three experts in psychiatric mental health nursing. They were from different academic categories, i.e., professor and assistant professor in faculty of nursing at Benha University. To ascertain relevance, clarity and completeness of the tools, experts elicited responses, which were either agree or disagree for the content reliability.

Voluntary participation and right to refuse to participate in the study was emphasized to the subjects.

\section{Ethical considerations:}

The objective and aim of the study were clarified by the researcher to every participant in the study, oral consent obtained from each patient before conducting the interview; the subjects who agreed to participate in the study were assured about the confidentiality and anonymity of the study. They were informed that they could withdrawal from the study at any time. Acceptance to participant in the study was taken through oral consent.

\section{A pilot study:}

A pilot study was under taken after the adaptation of the tools and before starting the data collection. It was conducted on 5 family caregivers of patient with bipolar disorder.

The purpose of the pilot study was to test the applicability, feasibility and clarity of the tools. In addition, it served to estimate the approximate time required for interviewing the family caregivers as well as to find out any problems that might interfere with data collection.

After obtaining the result of the pilot study, the necessary modifications of tools as, excluded questions, added questions \& revised were done then final format was developed under the guidance of supervisors. Family caregivers who participated in the pilot study were included in the main study sample.

\section{Field work}

-The researcher introduced herself to the patients then explained the aim of the study to every one of them. Consent was taken from every one of them before data collection.

-The researcher collects data from patients and their caregivers (20 patient and their caregivers) during their visit in wards.

-The researcher attended the mental psychiatric outpatient clinic to complete the number of sample (60 patients and their caregivers), two days (Saturday and Tuesday) per week, from 9.00 AM. To 2.00 PM.

-The data collection lasted over 6 months starting from the beginning of April to the 


\section{Ola Arafa, Sayeda Ahmed, Mawaheb Mahmoud and Doha Abdel-Baseer}

end of to October 2020. A number of interviewed caregivers per week ranged from 1-2. Sometimes, during the six-month period for collecting data, there were some days that no patient was in the outpatient clinic due to the pandemic of covid-19.

-The researcher interviewed each caregiver individually and briefly explained the nature and the purposes of the study, and asked for participation. All caregivers were informed that participation is voluntary.

\section{Statistical analysis :}

All data collected were organized, coded, computerized, tabulated and analyzed by using The Statistical Package for Social Science (SPSS programs version 20), which used frequencies and percentages for qualitative descriptive data, Chi-square was used for relation tests, mean and standard deviation was used for quantitative data and person correlation coefficient (r) was used for correlation analysis and degree of significance was identified. A highly statistical significant difference was considered if $\mathrm{p}$-value $<0.01$, statistical significant difference was considered if $\mathrm{p}$ value $<0.05$ and non-statistical significant difference was considered if $p$-value $p>$ 0.05 .

\section{Results:}

Table (1) Shows the socio- demographic data of patients, it was cleared that less than half $(46.3 \%)$ of the studied patients was in the age group of 18-25 years with a mean age of 27.38 \pm 8.56 years. Concerning gender, more than half $(58.8 \%)$ of them were male. Additionally more than half $(51.3 \%)$ of them were single. In addition; regarding occupation, less than two-thirds (63.8\%) of them were unemployed.

Table (2) Revealed that about one-third
(33.8\%) of caregivers were in the age group of (46-55) with a mean age of 35.72 \pm 9.31 years .As regrades gender, less than two-third (63.8\%) of them were female. Concerning degree of relation, the majority $(93.7 \%)$ of them were first relation. Also number of family members, more than half $(58.7 \%)$ of them were (4-6). Additionally, marital status less than one-third $(30.0 \%)$ of them were married. In relation to level of education, about one-third $(33.7 \%)$ of them were read and write. In addition, occupation more than half $(52.5 \%)$ of them were unemployed. Regarding number of caring hour for patient per day, about two-third (66.2\%) of them were more than 12 hours. Moreover, caring of other family members more than threequarters $(77.5 \%)$ of them were caring of other. Furthermore, helped by other in caring patient three-quarters $(75.0 \%)$ of them were helped by others. Increasingly, help in treatment costs the majorities $(81.3 \%)$ of them were helped by their families.

Table (3) Clears that the duration of patients illness, were more than two-fifth (43.8\%) less than 5 years. Regarding age at onset of the disease, three-quarters $(75.0 \%)$ of them were less than 20 years. Concerning number of hospital admissions, more than half (52.5\%) of them were once.

Figure (1) Reveals that, more than two-fifth $(41.3 \%)$ of the studied patients were mild behavior, about one-quarter $(25 \%)$ of them had low behavior, also one-quarter $(23.7 \%)$ of them were moderate behavior, while the minority (10\%) of them had severe behavior.

Figure (2) Reveals that, more than half (52.5\%) of caregivers had mild response to patient behavior, more than one-third $(37.5 \%)$ of them had low response, while the minority (5\%) of them had moderate and high response. 
Figure (3) Clears that more than half $(52.5 \%)$ of patients had moderate symptoms, less than one-third (30\%) of them had low symptoms while less than one-fifth (17.5\%) of them had high symptoms.

Table (4) clarifies that; there was a highly statistically significant relation between total caregivers' expressed emotion and socio- demographic characteristics of caregivers in all items except degree of relation and number of family members $(\mathrm{p} \leq 0.001)$.

Table (5) Illustrates that, there was a positive statistically correlation between total caregivers' expressed emotion and total patients' clinical outcomes.

Table (1): Socio- demographic data of studied patients $(\mathrm{N}=80)$

\begin{tabular}{|c|c|c|}
\hline Socio- demographic data of patients & No & $\%$ \\
\hline \multicolumn{3}{|l|}{ Age } \\
\hline $18-<25$ & 37 & 46.3 \\
\hline $25-<35$ & 28 & 35.0 \\
\hline $35-<45$ & 10 & 12.5 \\
\hline$\geq 45$ & 5 & 6.2 \\
\hline \multicolumn{3}{|c|}{ Mean \pm SD $=27.38 \pm 8.56$} \\
\hline \multicolumn{3}{|l|}{ Gender } \\
\hline Male & 47 & 58.8 \\
\hline Female & 33 & 41.2 \\
\hline \multicolumn{3}{|l|}{ Marital status: } \\
\hline Single & 41 & 51.3 \\
\hline Married & 9 & 11.3 \\
\hline Widowed & 5 & 6.2 \\
\hline Divorced & 25 & 31.2 \\
\hline \multicolumn{3}{|l|}{ Occupation } \\
\hline Unemployed & 51 & 63.8 \\
\hline Private business & 19 & 23.8 \\
\hline Private sector & 5 & 6.2 \\
\hline Governmental sector & 5 & 6.2 \\
\hline
\end{tabular}


Table (2): Socio-demographic data of studied caregivers $(\mathrm{N}=80)$

\begin{tabular}{|c|c|c|}
\hline Socio-demographic data of caregivers & No & $\%$ \\
\hline \multicolumn{3}{|l|}{ Age } \\
\hline $25-<35$ & 10 & 12.4 \\
\hline $35-<45$ & 20 & 25.0 \\
\hline $45-<55$ & 27 & $\overline{33.8}$ \\
\hline$\geq 55$ & 23 & 28.8 \\
\hline \multicolumn{3}{|c|}{ Mean \pm SD $=35.72 \pm 9.31$ Range: $23-55$ years } \\
\hline \multicolumn{3}{|c|}{ 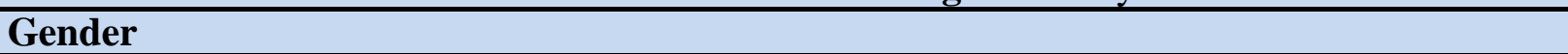 } \\
\hline Male & 29 & 36.2 \\
\hline Female & 51 & 63.8 \\
\hline \multicolumn{3}{|l|}{ Degree of relation } \\
\hline First relation & 75 & 93.7 \\
\hline Second relation & 5 & 6.3 \\
\hline \multicolumn{3}{|l|}{ Number of family members } \\
\hline$<4$ & 14 & 17.5 \\
\hline $4-<6$ & 47 & 58.7 \\
\hline $6-<8$ & 19 & 23.8 \\
\hline$\geq 8$ & 0 & 0.0 \\
\hline \multicolumn{3}{|l|}{ Marital status } \\
\hline Single & 14 & 17.5 \\
\hline Married & 24 & 30.0 \\
\hline Widowed & 23 & 28.8 \\
\hline Divorced & 19 & 23.7 \\
\hline \multicolumn{3}{|l|}{ Level of education } \\
\hline Illiterate & 19 & 23.7 \\
\hline Read and write & 27 & 33.7 \\
\hline Secondary education & 19 & 23.8 \\
\hline High education & 15 & 18.8 \\
\hline \multicolumn{3}{|l|}{ Occupation } \\
\hline Unemployed & 42 & 52.5 \\
\hline Free business & 14 & 17.5 \\
\hline Private sector & 19 & 23.8 \\
\hline Governmental sector & 5 & 6.2 \\
\hline \multicolumn{3}{|l|}{ Number of caring hours for patient per day } \\
\hline$\leq 12$ hours & 27 & 33.8 \\
\hline$>12$ hours & 53 & 66.2 \\
\hline \multicolumn{3}{|l|}{ Caring of other family members } \\
\hline Yes & 62 & 77.5 \\
\hline No & 18 & 22.5 \\
\hline \multicolumn{3}{|l|}{ Do you helped by other in caring patient? } \\
\hline Yes & 60 & 75.0 \\
\hline No & 20 & 25.0 \\
\hline \multicolumn{3}{|l|}{ Help in treatment costs } \\
\hline Family & 65 & 81.3 \\
\hline Work & 0 & 0.0 \\
\hline Relatives & 15 & 18.7 \\
\hline Friends & 0 & 0.0 \\
\hline
\end{tabular}


Table (3):- Clinical data of the studied patient $(N=80)$

\begin{tabular}{|c|c|c|}
\hline Clinical data of the studied patient & No & $\%$ \\
\hline \multicolumn{3}{|l|}{ Duration of illness } \\
\hline$<5$ years & 35 & 43.8 \\
\hline $5-\leq 10$ years & 24 & 30.0 \\
\hline$>10$ years & 21 & 26.2 \\
\hline \multicolumn{3}{|l|}{ Age at onset of the disease } \\
\hline$<20$ years & 60 & 75.0 \\
\hline $20-<30$ & 20 & 25.0 \\
\hline $30-<40$ & 0 & 0.0 \\
\hline \multicolumn{3}{|l|}{$\geq 40$} \\
\hline \multicolumn{3}{|l|}{ Number of hospital admissions } \\
\hline Once & 42 & 52.5 \\
\hline Twice & 24 & 30.0 \\
\hline Three times & 9 & 11.3 \\
\hline$\geq$ four times & 5 & 6.2 \\
\hline
\end{tabular}

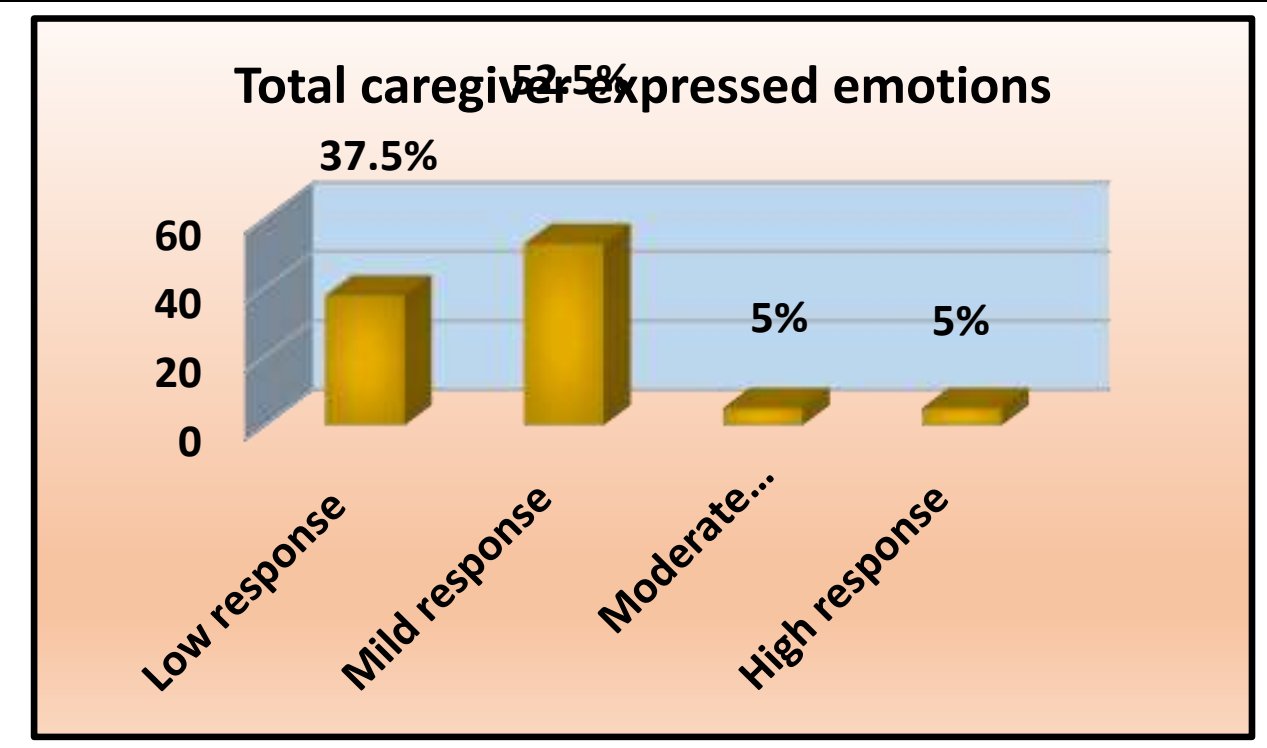

Figure (1): percentage distribution of total caregiver expressed emotion ( $\mathrm{N}=80)$

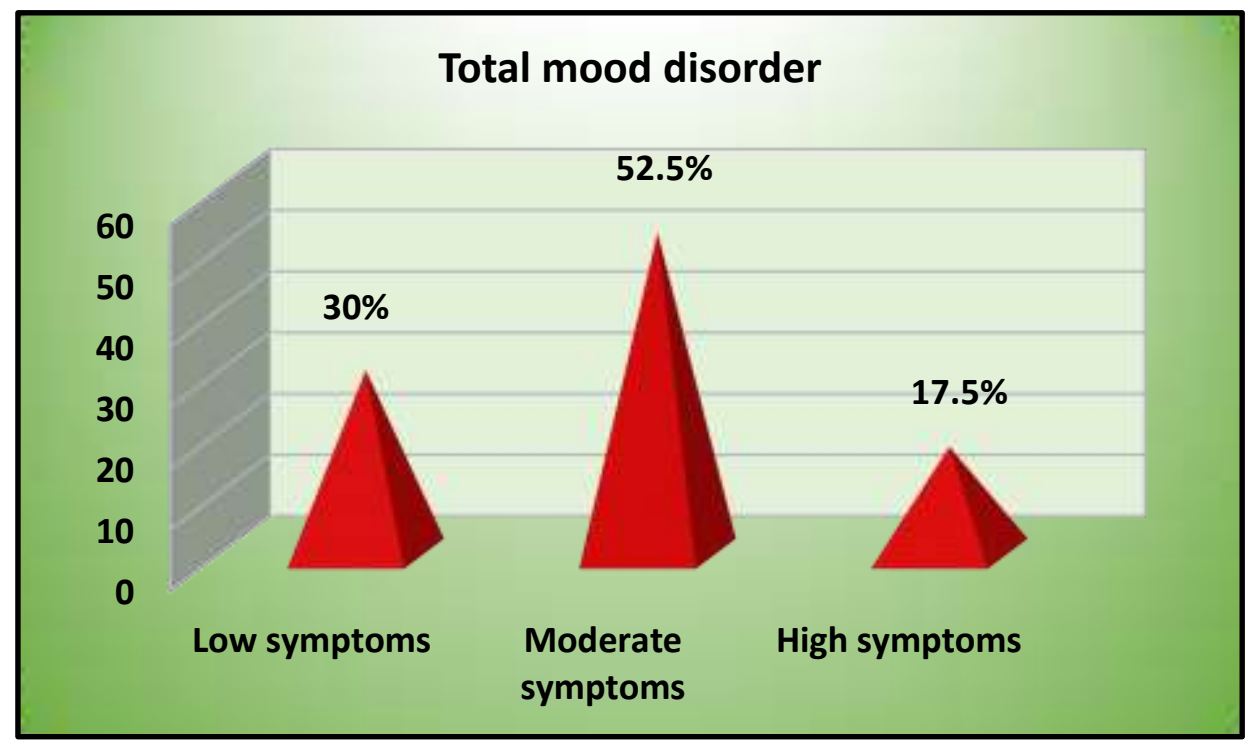

Figure (2): percentage distribution of mood disorder symptoms $(\mathrm{N}=80)$ 
Table (4): Relation between Socio-demographic characteristics of caregivers and total caregivers' expressed emotion

\begin{tabular}{|c|c|c|c|c|c|c|c|c|c|c|}
\hline \multirow{3}{*}{$\begin{array}{c}\text { Socio-demographic } \\
\text { characteristics of } \\
\text { caregivers }\end{array}$} & \multicolumn{8}{|c|}{ Total caregivers' expressed emotion. } & \multirow{3}{*}{$\mathrm{X} 2$} & \multirow{3}{*}{ P-value } \\
\hline & \multicolumn{2}{|c|}{$\begin{array}{c}\text { Low } \\
\text { response }\end{array}$} & \multicolumn{2}{|c|}{ Mild response } & \multicolumn{2}{|c|}{$\begin{array}{l}\text { Moderate } \\
\text { response }\end{array}$} & \multicolumn{2}{|c|}{$\begin{array}{c}\text { High } \\
\text { response }\end{array}$} & & \\
\hline & No & $\%$ & No & $\%$ & No & $\%$ & No & $\%$ & & \\
\hline \multicolumn{11}{|l|}{ Age } \\
\hline $25-35$ & 10 & 33.3 & 0 & 0 & 0 & 0 & 0 & 0 & \multirow{4}{*}{49.53} & \multirow{4}{*}{$.000 * *$} \\
\hline $36-45$ & 5 & 16.7 & 15 & 35.7 & 0 & 0 & 0 & 0 & & \\
\hline $46-54$ & 5 & 16.7 & 22 & 52.4 & 0 & 0 & 0 & 0 & & \\
\hline$\geq 55$ & 10 & 33.3 & 5 & 11.9 & 4 & 100 & 4 & 100 & & \\
\hline \multicolumn{11}{|l|}{ Gender } \\
\hline Male & 5 & 16.7 & 24 & 57.1 & 0 & 0 & 0 & 0 & 17.46 & $.001 * *$ \\
\hline Female & 25 & 83.3 & 18 & 42.9 & 4 & 100 & 4 & 100 & & \\
\hline \multicolumn{11}{|l|}{ Degree of relation } \\
\hline First relation & 25 & 83.3 & 42 & 100 & 4 & 100 & 4 & 100 & 8.88 & $.031 *$ \\
\hline Second relation & 5 & 16.7 & 0 & 0 & 0 & 0 & 0 & 0 & & \\
\hline \multicolumn{11}{|c|}{ Number of family members } \\
\hline Less than 4 & 5 & 16.7 & 9 & 21.4 & 0 & 0 & 0 & 0 & 17.10 & $.009 *$ \\
\hline $4-6$ & 20 & 66.6 & 23 & 54.8 & 0 & 0 & 4 & 100 & & \\
\hline 7- 8 & 5 & 16.7 & 10 & 23.8 & 4 & 100 & 0 & 0 & & \\
\hline$>8$ & 0 & 0 & 0 & 0 & 0 & 0 & 0 & 0 & & \\
\hline \multicolumn{11}{|l|}{ Marital status } \\
\hline Single & 5 & 16.7 & 9 & 21.4 & 0 & 0 & 0 & 0 & 38.82 & $.000 * *$ \\
\hline Married & 15 & 50 & 9 & 21.4 & 0 & 0 & 0 & 0 & & \\
\hline Widowed & 10 & 33.3 & 9 & 21.4 & 0 & 0 & 4 & 100 & & \\
\hline Divorced & 0 & 0 & 15 & 35.8 & 4 & 100 & 0 & 0 & & \\
\hline \multicolumn{11}{|l|}{ Level of education } \\
\hline Illiterate & 10 & 33.3 & 5 & 11.9 & 0 & 0 & 4 & 100 & 29.86 & $.000 * *$ \\
\hline Read and write & 5 & 16.7 & 18 & 42.9 & 4 & 100 & 0 & 0 & & \\
\hline Secondary education & 10 & 33.3 & 9 & 21.4 & 0 & 0 & 0 & 0 & & \\
\hline High education & 5 & 16.7 & 10 & 23.8 & 0 & 0 & 0 & 0 & & \\
\hline \multicolumn{11}{|l|}{ Occupation } \\
\hline Unemployed & 20 & 66.6 & 18 & 42.9 & 0 & 0 & 4 & 100 & 40.66 & $.000 * *$ \\
\hline free business & 0 & 0 & 10 & 23.8 & 4 & 100 & 0 & 0 & & \\
\hline Private sector & 5 & 16.7 & 14 & 33.3 & 0 & 0 & 0 & 0 & & \\
\hline Governmental sector & 5 & 16.7 & 0 & 0 & 0 & 0 & 0 & 0 & & \\
\hline \multicolumn{11}{|c|}{ Number of caring hours for patient per day } \\
\hline$\leq 12$ hours & 10 & 33.3 & 9 & 21.4 & 4 & 100 & 4 & 100 & 18.55 & $.000 * *$ \\
\hline More than 12 hours & 20 & 66.7 & 33 & 78.6 & 0 & 0 & 0 & 0 & & \\
\hline \multicolumn{11}{|c|}{ Caring of other family members } \\
\hline Yes & 30 & 100 & 28 & 66.7 & 0 & 0 & 4 & 100 & 26.47 & $.000 * *$ \\
\hline No & 0 & 0 & 14 & 33.3 & 4 & 100 & 0 & 0 & & \\
\hline \multicolumn{11}{|c|}{ Do you be helped by other in caring patient? } \\
\hline Yes & 15 & 50 & 37 & 88.1 & 4 & 100 & 4 & 100 & 16.50 & $.001 * *$ \\
\hline No & 15 & 50 & 5 & 11.9 & 0 & 0 & 0 & 0 & & \\
\hline Help in treatment co & & & & & & & & & & \\
\hline Family & 15 & 50 & 42 & 100 & 4 & 100 & 4 & 100 & 30.76 & $.000^{* * *}$ \\
\hline Work & 15 & 50 & 0 & 0 & 0 & 0 & 0 & 0 & & \\
\hline Relatives & 0 & 0 & 0 & 0 & 0 & 0 & 0 & 0 & & \\
\hline Friends & 0 & 0 & 0 & 0 & 0 & 0 & 0 & 0 & & \\
\hline
\end{tabular}


Table (5): Correlation between total caregivers' expressed emotion and total patients' clinical outcomes (degree of mood disorder) $(\mathbf{N}=\mathbf{8 0})$.

\begin{tabular}{|l|c|c|}
\hline \multicolumn{2}{|c|}{ Variables } & Total caregivers' expressed emotion \\
\hline Total patients' clinical outcomes (degree of mood & $\mathbf{R}$ & P value \\
\cline { 2 - 3 } disorder) & .043 & .708 \\
\hline \multirow{2}{*}{ Discussion: } & $\begin{array}{l}\text { incidence rates of bipolar I disorder } \\
\text { throughout adult life. }\end{array}$
\end{tabular}

The result of the present study revealed that socio- demographic data of studied patients. Regarding age of patients, the findings of the current study cleared that less than half was in the age group of 18-25 years with a mean age of 27.38 \pm 8.56 years. The findings agreed with (Stephen, 2020) who found that the age at onset of type-I bipolar disorder (BPD) typically averages 12-24 years The second most frequent age range of onset is 20-24 years. This results disagreed with (Shradha, et al, 2019) who found that the majority of patients suffering from bipolar disorder have an onset prior to the fifth decade of their lives, similarly (Jessica et al, 2019) found that the age of BD subjects with later age of onset.

Concerning gender of patients, the present study illustrated that more than half were male, from researcher point of view This may have been due to male patients were usually carrying the burden of financial responsibility of the family; their illness made them unable to take the responsibility for their families and lead to relapse. This result is in accordance with (Pradyumna, et al, 2020) who found that more than two thirds of patients were males. In contrast with (Kennedy, 2020) who studied (Gender Differences in Incidence and Age at Onset of Mania and Bipolar Disorder in Camber well, England), found that women had higher
As regards to marital status of patients, more than half were single; this might be due to the early onset of the illness. These results were consistent with (Caroline, et al 2020) who indicated that more than two fifth of her sample were single additionally (Kengo et al, 2019) who found that about half of the sample unit were single. From researcher point of view this result may be due to less than half of the studied patients was in the age group of 18-25years.

Regarding, occupation, less than two-thirds of them were unemployed this results come with the harmony with (Andrea, et al 2019) who stated that individuals with bipolar disorder often experience significant interpersonal and occupational impairment. This may be due to those patients with bipolar disorder typically had long-standing deficits in their performance of even the most basic social roles and skills required for work.

Regarding Socio-demographic data of studied caregivers the findings of the current study represented that about one-third of caregivers were in the age group of (46-55) with a mean age of $35.72 \pm 9.31$ years. This result can attribute to the younger family caregivers are able to take responsibilities of caregiving of their close relatives. This result came in the same line with (Nayereh, et al 2019) who found that the age of caregivers ranged from (40-60). 
As regrades gender of the studied caregivers, the findings of the present study cleared that less than two-third were female, (Navidian et al, 2017) found that most caregivers in their study were women who also were housewives. Contradictory findings were found by (Gupta et al, 2019), who reported that the majority of the caregivers were males. From the researcher point of view, this result could be due to the care given is often expected performed by females, as by nature of their position and characteristics are taking the major responsibility of caring for their ill relative. So, they may be trusted more in their ability to care for the patient with bipolar disorder who needs specific care.

Concerning degree of relation of caregivers, the present study cleared that the majority were first relation. These result in congruent with (Ayush, et al 2020) who reported that the majority of caregivers were first relation. Regarding marital status of caregivers, less than one-third was married. While contradicted by (David et al, 2018) who found that three quarter of caregivers were divorced. As regards level of education of the studied caregivers, the present study clarifies that about one-third was read and writes, from the researcher point of view this may be due to age distribution of caregivers were in the age group of (46-55) and rural culture that contribute agriculture than education.

Concerning occupation of the studied caregivers, the present study revealed that more than half of the studied caregivers were unemployed this result was consistent with (Fahad et al, 2019) whose study revealed the same result, from researcher point of view this might be due to less than two-third of them were females have also household work.

As regard caring of other family members, the present study cleared that more than threequarters of the studied caregivers were caring of other. This result goes along with (Oshodi et al, 2018) which reported about helping in the treatment of mental illness are one by the other family members. From researcher point of view this might be due to less than onethird of them were married and more than one-quarter were widowed and may have children and more responsibilities.

Furthermore, helped by other in caring patient the present study cleared that threequarters of caregivers were helped by others. This result come with the harmony with a study done by (Iseselo et al, 2016) who found that more of caregivers helped by their spouses and sons this might be due to more than three-quarters of them lived in rural areas, and culture of rural areas concentrates on relatives living together and may be in the same house.

Concerning, help in treatment costs the findings of the current study cleared that the majorities of the studied caregivers were helped by their families in treatment costs from researcher point of view this may be due to that family play an essential role in bearing patient's treatment costs. This result goes along with (Mark, et al 2019) who stated that costs for the treatment of illness are often covered by insurance. However, Sociodemographic data of studied patient and caregivers, a study done by (Mihir, et al, 2019) titled (Burden and Expressed Emotion in Caregivers of Schizophrenia and Bipolar Affective Disorder Patients) Sociodemographic variables such as sex, 
marital status, and residence. There were no significant differences in the sociodemographic-profile of patients or caregivers in both the groups. This may be due to, from researcher's view, in rural areas the most families lived in the same village and probably the same home.

Regarding Clinical data of the patient the findings of the current study cleared that the duration of patients illness, were more than two-fifth less than 5 years this might be due to age distribution of patients (18-25) this result in consistence with (Stephen, 2020) who found that the most cases of bipolar disorder commence when individuals are aged 15-19 years.

Regarding age at onset of the disease, the findings of the current study showed that three-quarters of the studied patient were less than 20 years this result in congruent with who reported that more than three fifths of bipolar patients experienced illness before the age of 20 years in opposite with (Lindsay, et al, 2016) who revealed that the age of onset of bipolar disorder in less than three quarter of the patients occurred in childhood and for more than one fifth of them occurred in adolescence.

Concerning number of hospital admissions, the findings of the current study clarified that more than half of the studied patient was once. These result in congruent with (Muneer, 2016) whose study revealed that the majority of patients were the first admission, in opposite with (Peters et al, 2016) who revealed that greater likelihood of observed hospitalization. From researcher point of view these results could be due to age distribution of patients (18-25) from researcher point of view in this early age the patient at the beginning of life try to get job, maintain drug intake treatment and supported by families in caring.

In relation to total caregiver expressed emotion, the current study clarified that more than half of caregivers had mild response to patient behavior. This result was in harmony with (Yadav, 2018) in a study titled (Burden and Expressed Emotion in Caregivers of schizophrenia and Bipolar Affective Disorder Patients) who stated that, family caregivers of patient experienced mild and low expressed emotion toward their patients. Similarly (Kaur 2020), whose found that most of caregivers of bipolar patients have mild response to patient behavior.

This can be interpreted as a significant percent of caregivers were from rural area that provides social support more than urban areas On other hand, these results opposite to study conducted by (Hamad, 2017) in study entitled "Personal constructs in dementia caregiving: the family caregiving experience of people living with bipolar disorder in Egypt". He noted that, family caregivers of patient with bipolar disorder reported higher level of expressed emotion. From the researcher point of view, these results might be due to the nature of our culture. It is commonly known that Egyptian family is more accepting and supportive of their loved ones, as it has a sense of commitment to an unchangeable situation.

Concerning mood disorder symptoms, the current study cleared that more than half of patients had moderate symptoms. These results were consistent with a study done by (Zachary, et al 2018) entitled "Expressed emotion, emotional distress, and individual and familial history of affective disorder among parents of adolescents with bipolar 
disorder" that showed that the majority of patient having a stable moderate symptoms.

As regards Relation between Sociodemographic characteristics of caregivers and total caregivers' expressed emotion, the current study clarified that, there was a highly statistically significant relation between them in all items except degree of relation and number of family members. This results come with the harmony with a study done by (Mihir, et al, 2019) titled (Burden and Expressed Emotion in Caregivers of Schizophrenia and Bipolar Affective Disorder Patients) who states that the role of demographic variables in burden of care was examined in this study a positive correlation among the age of caregivers, education, and burden was observed suggesting that with the advancing age of caregivers, there is an increment in the magnitude of the perceived burden. When caregivers were older, they were more worried about the future of their ill family member that who will take care of them in future, and also that they cannot provide care well to the ill member of the family.

On the other hand, the result of current study differed from study conducted by (Bressert, 2019) entitled "Emotional reactivity to daily life stress in spousal caregivers of people with dementia". The study emphasized that, age, gender, occupation, income and care intensity (i.e. weekly hours of contact with and care for the patient with dementia) didn't impact on caregivers' emotional reactivity to daily life

From researcher opinion, these results of the current study may be due to in some developing countries as in Egypt; the personal characteristics may influence the direction of the expressed emotion and play an exacerbating or buffering role in emotional reactivity to daily life stress, for example when the caregivers are unemployed this cause negative impact on the financial situation of the family thus correlated with more worry, stress and negative expressed emotion. Moreover, the degree of relation with the patient was very important in determine the level of expressed emotion as the female caregivers were more involved in the supervision of the patient, so they expressed more worry and emotional over involvement toward patient.

Regarding Correlation between total caregivers' expressed emotion and total patients' clinical outcomes, the current study illustrated that, there was a positive statistically correlation between total caregivers' expressed emotion and total patients' clinical outcomes. These findings supported by (Souzan, 2018) in the study titled "Resilience, burden, and quality of life in Egyptian family caregivers of patients with schizophrenia" The study indicated a significant positive correlation between resilience level and quality of life. Similarly, (Sharma, 2017) who states that there were a positive correlation between social support and patient well-being scores. On the contrary, (Alzahrani et al, 2017) who revealed that caregiving burdens were negatively correlated with both resilience and quality of life. Moreover, family caregivers have moderate level of resilience, and approximately two-thirds of them have poor overall quality of life and experiencing moderate to severe burden. 


\section{Conclusion:}

The present study revealed that more than two-fifth of the studied patients was mild behavior, while the minority of them had severe behavior. More than half of caregivers had mild response to patient behavior; more than one-third of them had low response, while the minority of them had moderate and high response, and this answered the research question about the forms of expressed emotions of the caregivers.

Also, it is observed that, there was a positive statistically correlation between total caregivers' expressed emotion and total patients' clinical outcomes, and this answered the research question about the relationship between the caregiver's expressed emotion and clinical outcomes of patients with bipolar disorder.

\section{Recommendation:}

- Designing a systematically continuous family intervention programs in psychiatric hospitals that provide proper information and psychological support

- Caregivers' intervention should be planned on the basis of a careful assessment of the social resources, coping strategies and interpersonal skills of each relative.

- Emphasis on social support as a factor enhancing adaptive coping mechanisms because conflict of caregiving may reduce effective coping ability.

\section{References:}

Abo-Almagied, S. (1993). Psychiatric assessment of families in Schizophrenic Patients. Unpublished Doctorate Thesis. Cairo University. Faculty Of Medicine Alzahrani, S., Fallata, E., Alabdulwahab, M., Alsafi, W.\&Bashawri J.(2017).
Assessment of the burden on caregivers of patients with mental disorders inJeddah, Saudi Arabia. BMC Psychiatry 17:202

Andrea, G., Luke, J., Natasha, .S, Tamsyn, E. Van, $R \quad \&$ Kim L. (2019).Sex Differences In schizophrenia, bipolar disorder, and post-traumatic stress disorder: Are gonadal hormones the link?, British Journal of Pharmacology 10.1111/bph. 14584, 176, 21, (4119 4135), (2019).

Ayush, S., Ritu, N. \& Sandeep, G. (2020). Correlates of expressed emotions as perceived by patients with bipolar disorder International Journal of Social. Psychiatry, 10.1177/0020764020966633,

Bortolato B, Miskowiak KW, Köhler CA, Vieta E, Carvalho AF (2020). systematic review of meta-analyses". Neuropsychiatric Disease and Treatment. 11: 3111-3125

Bressert, S. (2019). Depression symptoms (major depressive disorder). Psych Central Retrieved on August 1, 2019.

Caroline, B., Iwona, C.\& Kristy, D. (2020). Patients with borderline personality disorder and bipolar disorder: a descriptive and comparative study, Psychological Medicine, 10.1017/S0033291720000215, (1-12), (2020).

Craddock, N. \& Sklar, P. (2016). "Genetics of bipolar. Lancet . 381 (9878): 1654-1662.

David, C., Carolynne, W., James, C., Michael, B., Lesley, B., Sue, L., Greg, M., Isaac, S., Leon, P. \& Monica, G. (2018). Group-based psychosocial intervention for bipolar disorder: randomised controlled trial, British Journal of Psychiatry 10.1192/bjp.bp.108.058263, 196, 5, (383388), (2018).

Di Giacomo E, Aspesi F, Fotiadou M, Arntz A, Aguglia E, Barone L et al. (2017). Unblending borderline personality and bipolar disorders. J Psychiatr Res 91:90-97. 
El- Rasheed hospital (2019). https://alrashid-hospital.com/test.

Fahad, D., Deemah, A., AlAteeq, N., Sarah I, Riham S Alhenaki, A. \& Salamah, A. (2019). Public Awareness, Beliefs, And Attitudes Toward Bipolar DisorderIn Saudi Arabia Neuropsychiatr Dis Treat. 2019; 15: 2809- 2818. Published online 2019 Sep 27. doi: 10.2147/NDT.S209037

Fallon, G., James, D. \& Todd, B. (2019). The Role of Relatives' Expressed Emotion and Personality Traits in Predicting Schizophrenia Relapse. 41, (1), pp 41-50.

Gupta, A., Solanki, R., Koolwal, G. \& Gehlot, S. (2019). Psychological well-being and burden in caregivers of patients with schizophrenia. Int J Med Sci Public Health 4:70-76.

Hamad, E. (2017). Personal Constructs in Dementia Caregiving: The Family Caregiving Experience of People Living with Dementia in Egypt. Electronic Thesis and Dissertation Repository. 4472. https b:// ir. lib. uwo. Ca /etd/4472.

Hirschfeld, R., Williams, J., Spitzer, R., et al (2000). Development and validation of a screening instrument for bipolar spectrum disorder: the Mood Disorder Questionnaire. AmJ Psychiatry. 2000;157:1873-1875.

Iseselo, M., Kajula, L. \& Yahya, K. (2016). The psychosocial problems of families caring for relatives with mental illnesses and their coping strategies: a qualitative urban based study in Dar es Salaam, Tanzania. BMC Psychiatry 16:146

Jessica, D., Ross, J., Balde, s., Giulia, S., Olav, N., Giovanni, G. \& Matthew, L. (2019). The Age of Onset of Bipolar Disorders, Age of Onset of Mental

Kaur, N. (2020). Caregiver's burden and social support among caregivers of schizophrenic patients. Delhi Psychiatry J 17:337-341.

Kengo, F., Wataru, U., Eri, H., Hanako, T.\& Yoshiyasu, K, (2019). Antidepressant activities of escitalopram and blonanserin on prenatal and adolescent combined stressinduced depression model: possible role of neurotrophic mechanism change in serum and nucleus accumbens.

Kennedy, M. (2020). Gender Differences in Incidence and Age at Onset of Mania and Bipolar Disorder Over a 35-Year Period in Camber well, England: Published Online:1 Feb 2005

https://doi.org/10.1176/appi.ajp.162.2.257

Kwok, T., Choy, J., \& Kavanagh, D. (2016). Measuring the expressed emotion in Chinese family caregivers of persons with mental illnesses: Validation of a Chinese version of the Family Attitude Scale. International Journal of Nursing Studies Volume 55, Pages 50-59.Disorders, 10.1007/978-3-319-72619-9,

(75-110), (2019).

Leff, J., Nehra, R., Malhotra, R. \& Kate, N. (2018). Influence of Relatives' Expressed Emotion on the Course of Schizophrenia in Chandigarh, The British Journal of Psychiatry Volume 151 Issue 2

Lindsay, M., Anthony, N., Geoffrey, B., Roberto, B. \& Sassi,S. (2016). Cortical thickness in bipolar disorder: a systematic review, Bipolar Disorders 10.1111/bdi.12362, 18, 1, (4- 18), (2016).

Lowyck, B., De Hert, M., Peeters, E., Wampers, M., Gilis, P. \& Peuskens, J.(2019). A study of the family burden of 150 family members of schizophrenic 65:730

Mark, Z., William, E., Theresa, A., Morgan, D., Iwona, C. \& Kristy, D. (2019). Psychosocial morbidity associated with bipolar disorder and borderline personality 
disorder in psychiatric out-patients: Psychiatry, 10.1192/bjp.bp.114.153569, 207, 04, (334-338), (2019).

Mihir, R., Nayak, T., Mallik, S.\& Hembram, M. (2019). Burden and Expressed Emotion in Caregivers of Schizophreniaand Bipolar Affective Disorder Patients:

Miklowitz, D.\&Chung, B. (2020). FamilyFocused Therapy for Bipolar Disorder: Reflections on 30 Years of Research.Fam Process. 2020 Sep;55(3):483-99. doi: 10.1111/famp.12237. Epub 2020 Jul 29.

Muneer, A. (2016). Staging models in bipolar disorder: A systematic review of the literature. Clin Psychopharmacol Neurosci. 2016;14:117-130. doi: $\quad 10.975$ 8/cpn.2016.14.2.117

Navidian, A., Kermansaravi, F. \& Rigi, S. (2017). The effectiveness of a group psychoeducational program on family caregiver burden of patients with mental disorders. BMC Research Notes 5:399

Nayereh, M., Effat, S., Farshid S., Lily, T. \& Ali, G. (2019). Comparative Analysis of Spouse's Burden and Quality of Life in Major Depressive Disorder and Bipolar I Disorder, Current Psychiatry Research ，15, 3, (193-198), (2019).

Oshodi, Y., Adeyemi, J., Ainal, O., Suleiman, T., Erinfolami, A. \& Umeh, C. (2018). Burden and psychological effects: caregiver experiences in a psychiatric outpatient unit in Lagos, Nigeria. Afr J Psychiatry 15:99-105.

Peters, A., West, A., Eisner, L., Baek, J. \& Deckersbach, T. (2016). The Burden of Repeated Mood Episodes in Bipolar I Disorder: Results From the National Epidemiological Survey on Alcohol and Related Conditions. The Journal of nervous and mental disease, 204(2), 87-94.
Pradyumna R., Sandeep G. \& Subho C. (2020). Coping with caregiving stress among caregivers of patients with schizophrenia, Asian Journal of Psychiatry, 10.1016/j.ajp.2020.102219, 54, (102219),

Sharma, M., Chakrabarti, S. \& Grover, S. (2016). Gender differences in caregiving among family - caregivers of people with mental illnesses. World J Psychiatry; 22, 6(1): 7-17.

Shradha, S., Saumitra, S. \& Nemlekar, A. (2019). implications for continuation treatment". Progress in Neurology and Psychiatry. 17 (3): 26-27Treatment for severe bipolar disorder The Lancet, Volume 382, Issue.

Souzan, A., Amal, A. \& Hosam, E. (2018). Resilience, burden, and quality of life in Egyptian family caregivers of patients with schizophrenia V:15 Issue : 2 P: 196204

Stephen, M. (2020). in what age groups is the onset of bipolar affective disorder (manic-depressive ill mostlikely https://www.

medscape.com/answers/286342- 101554/in what-age-groups-is-the-onset-of-bipolaraffective disorder-manic- depressiveillness-most-likely

Yadav, A. (2018). Burden and Expressed Emotion in Caregivers of schizophrenia and Bipolar Affective Disorder Patients: A Comparative Study 4(2):68)

Zachary, B., Millman, A., Marc, J., Weintraub, B. \& David, J. (2018). Expressed emotion, emotional distress, and individual and familial history of affective disorder among parents of adolescents with bipolar disorder; 270: 656-660 


\section{تأثير التعبيرات الانفعالية لمقدمي الرعايه على التتائج الإكلينيكية لمرضى إضطراب ثنائى القطب علا عرفه محمد كمال- سيدة أحمد عبد اللطيف ـ مواهب محمود زكى - ضحى عبدالبصير محمود}

اضطر اب ثنائي القطب هو اضطر اب عقلي يتميز المريض بنوبات منقطعة من الهوس أو الاكتئاب ، مع عدم وجود أعر اض بينهما. خلال هذه النوبات ، يعانى الأشخاص المصابون بالاضطر اب ثنائي القطب اضطر ابات في المزاج الطبيعي والنشاط النفسي ومستوى النشاط البدني الذي بتأثر بالمزاج وإيقاع الساعة البيولوجية والإدر الك. يمكن أن بظهر الهوس بمستويات متفاوتة من اضطر اب المزاج ، بدءًا من النشوة المرتبطة بالهوس الكلاسيكي إلى اضطر اب النطق والتهيج.. تهدف هذه الدراسة هو تقييم تأثير التعبيرات الإنفعاليه لمقدمى الرعاية على النتائج الأكلينيكية لمرضلى أضطر اب ثنائى القطب، تم إجراء الدراسة في مستشفى بنها للصحة النفسية و علاج الأدمان في مدينة بنها بمحافظة القليوبية. وهي تابعة للأمانة العامة للصحه النفسيه تم تحديد عينة مناسبة

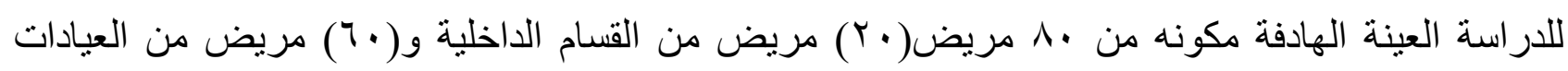
الخارجية (· r) من مقدمى الرعايه أثناء زيارة المريض فى الأقسام الداخلية و( • ؟) من مقدمى الرعايه الذين

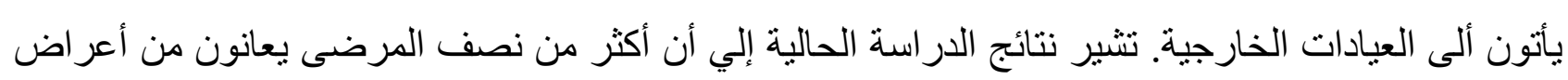
معتدلة ، كما لوحظ وجود علاقة إيجابية إحصائية بين إجمالي التعبيرات الأنفالية التي أعرب عنها مقدو الرعاية وإجمالي النتائج الأكلينيكية للمرضى ، وهذا أجاب على سؤال البحث حول العلاقة بين المشاعر التي أعرب عنها مقدم الر عاية والنتائج السريرية لمرضى الاضطر اب ثنائي القطب 